\title{
Sustainable stock market indices: A comparative assessment of performance
}

\author{
Iustina Alina Boitan ${ }^{*}$ \\ a Bucharest University of Economic Studies, Bucharest, Romania, iustinaboitan@yahoo.com. \\ ${ }^{*}$ Corresponding author.
}

Received: 14 December 2019; revised: 5 January 2020; accepted: 12 January 2020; published: 17 January 2020.

\begin{abstract}
The paper focuses on the sustainability stock market indices and investigates whether there is evidence of synchronization between the price return provided by sustainability indices calculated for various geographic regions. Due to data availability constraints, the analysis had been performed only for the Dow Jones Sustainability Indices family, which comprises six types of indices. It had been considered the daily price return time series recorded in the last 10 years (November 30, 2010 - July 26, 2019) by each of the six Dow Jones Sustainability Indices, and it had been applied to the Principal Components Analysis method. Our findings confirm the initial research assumption that sustainability indices build for certain geographical areas are more correlated and hence more synchronized than others. More specifically, sustainability indices which include companies from Europe, Japan, US, World developed countries and World best-in-class exhibit correlated price returns, and hence are synchronized while DJSI for emerging countries is far apart. Therefore, the first five categories of indices may act as a substitute for each other. A second conclusion is that both emerging markets' sustainability index and any of the five indices may be included in investors' portfolios for purposes related to risk diversification and hedging.
\end{abstract}

Keywords: stock market, responsible investments, sustainable stock exchanges, sustainability index, principal components analysis.

JEL codes: C38, G23.

\section{INTRODUCTION}

The starting point of this research is the need to raise awareness of the potential investors regarding the ethical, sustainable investment alternatives which provide not only financial and economic added value to the investors, but also to the society and the environment as a whole. In this regard, we intend to deepen the concept of ethical, sustainability stock market indices as a financial instrument which may represent a motivation for individual and institutional investors to become active investors on the stock market.

The concept of sustainable investment represents an innovative and dynamic segment of the stock market, for which several regulated markets have launched a series of sustainable stock market indices (e.g. Dow Jones Sustainability Indices - DJSI family, launched between 1999 and 2013). It emerged and developed in the context of the Sustainable Development Goals when several stock markets took the ambitious initiative of aligning their traditional activity with public policy goals targeting long-term sustainable development. More specifically, in 2009 the UN Secretary-General had launched the Sustainable Stock Exchanges - SSE Initiative having as mission the capacity building of stock exchanges and securities market regulators, the promotion of responsible investment in sustainable development and the stimulation of corporate performance on environmental, social and governance issues (SSE, 2019). Currently, it gathers 90 stock exchanges across the world.

In addition, the World Federation of Exchanges - WFE has launched in late 2018 a set of five Sustainability Principles representing a formal commitment taken by WFE members' in order to promote the sustainable finance agenda irrespectively the market development stage. Principle no. 4 explicitly supports the emergence of sustainable finance products, such as sustainability indices and the development of sustainability ratings. 
According to the European Sustainable Investment Forum-Eurosif (2011), socially responsible investments may be classified into three broad categories, namely:

- responsible investments, a term applicable to institutional investors who, in the process of investment decision making, take into account not only financial factors but also the long-term influence of environmental, social and governance (ESG) factors;

- socially responsible investment, a term used in relation to small individual investors which indicates the selection of companies that meet certain social and environmental predefined criteria, based on negative or positive screening practices;

- impact investing, addressed to investors interested both in adopting a socially responsible investment strategy and in monitoring the outcome of these strategies for their portfolio.

The aim of the paper is twofold: i) to perform an analysis of the sustainability stock market indices' distinct features, and ii) to investigate whether there is synchronization between the price return provided by sustainability indices calculated for various geographic regions. Increased synchronization suggests that, for portfolio diversification purposes, investors should try to place their funds in sustainability indices that aren't highly correlated in order to offset potential decreases of indices' price return with increases from other indices. The first section synthesizes the features and typology of sustainability indices, the second one presents the methodological details and the variables used, the third one illustrates and explains the results obtained while the last one concludes. Our findings confirmed the initial research assumption that sustainability indices build for some geographical areas are more correlated and hence more synchronized than others.

\section{LITERATURE REVIEW}

The International Finance Corporation - IFC report (2011) highlights the key role accomplished by sustainability indices, namely to help investors in identifying a company or financial institution's non-financial value, given by the adoption of the ESG (Environmental, social and governance) principles, and to allow markets to reward sustainable corporate performance.

Vives and Wadhwa (2012) emphasize that sustainability indices' purpose is to act as a reliable benchmark for sustainable investment. Apart from deepening the development of stock markets, they can also be used as an interest raising tool so that individual and institutional foreign and domestic investors are attracted to place their funds in responsible investments. The authors acknowledge also the potential exhibited by sustainability indices, particularly in emerging markets, of stimulating responsible business practices in those companies willing to be included in the index or already included.

Sustainability indices represent a green, sustainable finance instrument that cares "for the causes of environmental, social, and governance. It is an investment strategy that seeks to combine social and/or environmental benefits with financial returns, thus linking investor's social, ethical, ecological, and economic concerns" (Brzeszczynski and McIntosh, 2014, p.2).

Sustainability indices are stock market indices traded on regulated markets that exhibit some particular features than regular indices. More specifically, the index includes only the shares of companies and financial institutions that meet a range of economic, social and environmental criteria, while the process of admission, selection, and removal of companies into/from sustainability indices depicts its own characteristics and uses a best-inclass approach. In other words, the companies included in the index have to prove the fulfillment of several sustainability criteria better than the majority of their peers within a given industry. In addition, sustainability indices rely on ethical exclusion criteria so as to remove companies engaged in unsustainable activities. The most used exclusion criteria are related to companies' exposure to alcohol, tobacco, gambling, armaments, cluster bombs, firearms, landmines, adult entertainment, nuclear weapons, nuclear power generation, and nuclear power sales.

A report prepared at the request of the World Federation of Exchanges (Siddy, 2009), delineates between three broad categories of tradable sustainable indices, namely:

-broad-based indices, comprising shares issued by companies in all economic sectors. Companies selected for being included in the index must prove the implementation of their business strategies of social and environmental responsibility criteria. Some representative indices examples are the FTSE4Good series, the BM\&FBOVESPA Corporate Sustainability Index (ISE), the Johannesburg Stock Exchange Socially Responsible Investment Index, the NASDAQ OMX GES Sustainability Nordic Index, the Wiener Börse VÖNIX Sustainability Index. 
-sector-specific indices, which include only companies that operate in the same economic sector and show concern for the same sustainable development issue, focusing mainly on clean technology, sustainable energy, and environmental services. Examples include FTSE's Environmental Technology Index series, Deutsche Börse's DAXglobal Alternative Energy Index, the NASDAQ OMX Clean Edge Global Wind Energy Index, the NYSE Arca Cleantech Index.

-composite indices, gathering the features of the two main categories above. An example in this regard is the NYSE Euronext composite index launched in late 2008 which reconciles the characteristics of a broad-based index type (non-sector specific) but oriented to only one aspect of ESG: the climate change (the NYSE Euronext Low Carbon 100 Europe ${ }^{\circledR}$ Index).

Existing literature in this field is focused on comparisons between classical stock market indices and sustainability ones and assessments of return, risk and volatility linkages and spillover by employing various methodologies (Lopez et al. 2007; Tularam et al 2010; de Souza Cunha \& Samanez 2013; Charlo et al. 2015; Santis et al 2016; Jain et al. 2019). Our empirical approach is focused exclusively on sustainability indices performance comparison and uses a novel methodology for this strand of literature.

\section{METHODOLOGY}

The research question gravitates around the potential co-movement exhibited by sustainability indices' price returns, in order to uncover those geographic regions (European, US, Asian, developed and emerging markets) featuring an increased degree of correlation. The findings will support investors in their sustainability indices' decision-making process and in better diversifying their portfolio.

Keeping in mind that the IFC report (2011) argues the lack of uniform methodology for sustainability indices' construction in terms of selection criteria for companies included in their structure (hence being difficult to perform comparative analyses across various types of indices), it had been decided to focus on a single family of sustainability indices, namely the Dow Jones Sustainability Indices (DJSI).

We relied on daily price return time series recorded in the last 10 years (November 30, 2010 - July 26, 2019) by each of the six Dow Jones Sustainability Indices, by applying the Principal Components Analysis method. The choice for this family of indices resides in its broad geographical coverage, the sustainability indices being constructed distinctly for Europe, US, Japan, emerging markets, developed markets and at the global level. In addition, our choice is motivated by the fact that S\&P Dow Jones Indices represent iconic financial market indicators, the number of assets invested in products based on DJ indices being larger than those invested in indices from any other provider in the world.

Principal Components Analysis (PCA) is a statistical technique meant to extract meaningful, latent information in the initial dataset of variables and to reconcile those depicting high correlation into a single indicator. One of the defining features of this method is that it can identify certain patterns in a data set and extract certain information to highlight the differences and similarities between variables. PCA method is the most appropriate for the purpose of the analysis as it succeeds to capture the interconnectedness between the chosen indices.

Mathematically speaking, this method applies a linear transformation of the initial dataset of indices by projecting them in a lower-dimensional space which is represented by a subset of principal components characterized by the highest variance explained. The outcome of this statistical algorithm illustrates the correlation between each sustainability index and the components generated.

Prior to performing the PCA analysis, the time series of each DJSI index has been tested for stationarity by employing the Augmented Dickey-Fuller (ADF) test, then the Kaiser-Meyer-Olkin sample adequacy test has been performed. We applied the varimax method that maximizes variance, the Kaiser criterion, and the Cattell test so that the extracted factors best represent the information reflected by the initial set of DJSI indices.

\section{ANALYSIS AND RESULTS}

\subsection{Data description}

First, we proceeded to data analysis to uncover the statistical behavior of the time series and whether they exhibit a normal distribution. It had been computed the descriptive statistics which are summarized in Table 1 below.

The minimum daily price returns were recorded by European and US sustainability indices, meanwhile, the maximum levels belong to Japan and World sustainability indices. Standard deviation indicates the amplitude of data spread around its mean value. The highest variation is recorded by Japan DJSI, while the lowest variation is present in the case of Europe DJSI, followed by US DJSI. The coefficient of variation is a more 
robust statistic that exhibits the degree of variation among different time series. Values higher than $30 \%$ depict greater dispersion of values around their mean, meanwhile, values below $20 \%$ are considered good. DJSI for emerging markets proves to be the most stable, compared with other indices, meanwhile, Japan DJSI is persistently identified as recording the highest variability. According to the values recorded by skewness and kurtosis statistics, none of the six-time series exhibit a normal distribution.

Table 1. Descriptive statistics of DJSI indices family

\begin{tabular}{lrrrrrrrr}
\hline & No. obs. & Minimum & Maximum & Mean & $\begin{array}{c}\text { Std. } \\
\text { Deviation }\end{array}$ & $\begin{array}{c}\text { Coefficient of } \\
\text { variation }\end{array}$ & Skewness & Kurtosis \\
\hline Europe & 2482 & 71 & 138 & 107.91 & 17.226 & 0.16 & -.225 & -1.214 \\
US & 2475 & 89 & 226 & 144.10 & 36.083 & 0.25 & .434 & -.959 \\
Japan & 2482 & 590 & 1661 & 1085.08 & 319.900 & 0.295 & -.056 & -1.463 \\
Emerging & 1812 & 672 & 1238 & 991.18 & 98.471 & 0.09 & -.660 & .410 \\
Developed & 2482 & 745 & 1439 & 1061.53 & 161.685 & 0.152 & .235 & -.907 \\
World & 2482 & 856 & 1636 & 1208.72 & 179.173 & 0.148 & .274 & -.869 \\
\hline
\end{tabular}

Source: author, based on Eviews computations

A complementary analysis relates to examining the degree of correlation between the DJSI family of indices. The strength of the relationship of DJSI Europe with DJSI Japan and the US is very strong (exceeds 0.8), while the relationship with DJSI World and World developed markets proves to be strong. The same strength is applicable also for DJSI Japan and respectively DJSI US against the remaining indices. DJSI World best-inclass is strongly correlated with DJSI Europe, Japan, and the US (a correlation coefficient between 0.6 and 0.75 ), and highly correlated with DJSI World developed (the correlation is of 0.99). At the opposite is the DJSI Emerging market which exhibits a very weak correlation with DJSI Europe, Japan, and the US and moderate correlation with DJSI World developed markets and World best-in-class.

One reason for explaining these correlations may be the composition (breakdown) of individual indices. For example, a strong correlation between DJSI US and DJSI World developed is due to the large share hold by US companies (around 50\%) in the DJSI World Developed Index. The same is applicable for DJSI Europe, World developed and World best-in-class. The same European companies may be included in all the three indices above mentioned, hence contributing to increased synchronization between them. Another reason may be due to the transnational activity of large companies, which set up headquarters in a geographical region but perform activities in others, too.

Figure 1. Consolidated graph of DJSI indices family (natural logarithm of daily price returns)

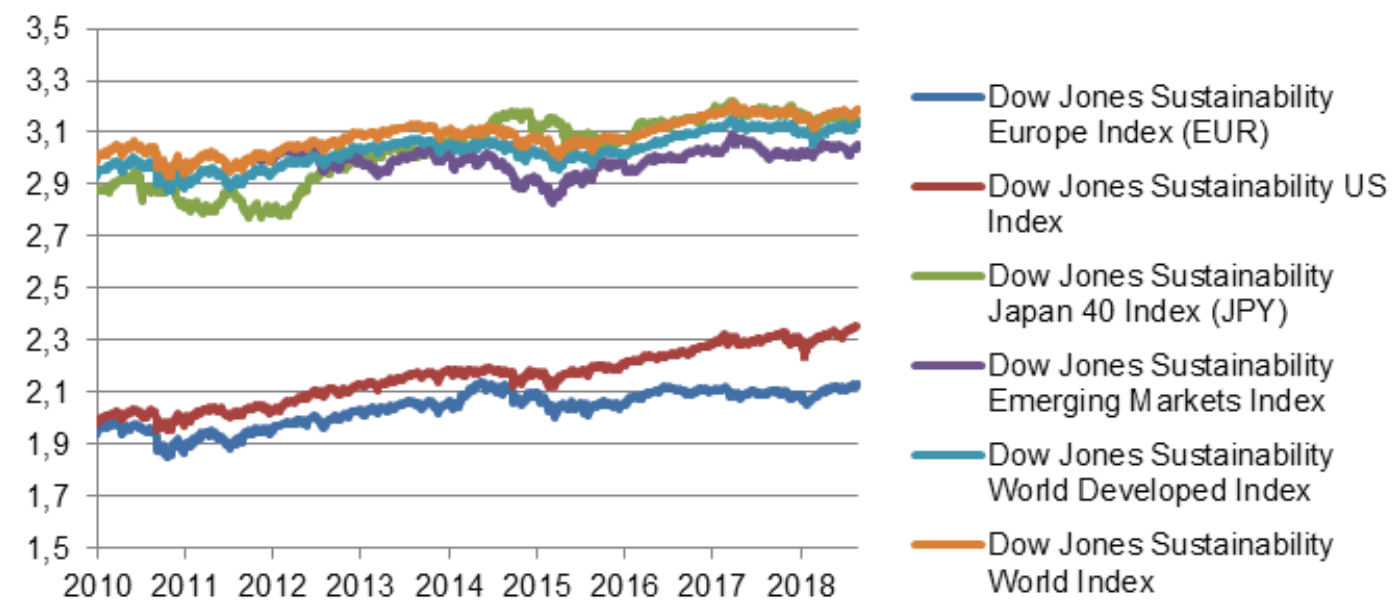

Source: author.

It has to be mentioned that the previous statistical analysis was conducted based on DJSI daily price returns denominated in various currencies (euro, Japanese yen, US dollars). When taking into account the exchange rate differences between indices and converting all of them into US dollars, for better comparison, one can notice that the degree of correlation between DJSI indices slightly changes. More specifically, the strength of the relationship between DJSI Europe and DJSI World developed, US and World best-in-class slightly decrease, still being considered strong. The correlation with DJSI Japan is almost identical as in the case when both 
indices were quoted in original currencies, and is considered to be very strong, meanwhile, the correlation with DJSI Emerging markets is very weak. As regards DJSI Japan, irrespective of the price returns are expressed in Japanese yen or US dollars, the strength of the correlation is almost identical, unchanged.

The stationarity of the time series has been tested by applying the ADF test. As the time series weren't stationary in level, it has been proceeded to taking the natural logarithm of the raw data. A visual plot of the DJSI indices family, representing the stationarity of each series under study is provided in Figure 1 . It can be noticed that the indices are grouped in two pairs, according to the daily levels of price returns: DJSI Europe and the US, and respectively DJSI Japan, Emerging markets, World Developed Markets, and World best-in-class. The DJSI World index seems to provide the most stable and attractive price returns.

The paper then proceeds with the econometric analysis, represented by the PCA.

\subsection{Findings and interpretation}

A mandatory stage in performing the PCA analysis requires testing the sample adequacy to reveal whether the dataset is appropriate for performing this type of analysis. The econometric theory proposes two types of tests, namely the Kaiser-Meyer-Olkin (KMO) adequacy test and Bartlett test. A rule of thumb states that the KMO statistic has to be larger than the 0.5 thresholds in order to ensure the presence of increased correlations between variables and to allow the extraction of reliable principal components. Bartlett test (test of sphericity) indicates whether the correlation matrix is an identity matrix and hence the extraction of components would be inappropriate. A probability associated with this test ranging below the $5 \%$ threshold rejects the null hypothesis and designates that the correlation matrix is not an identity matrix. Therefore, the two tests represent a minimum requirement, which must be fulfilled before any factor analysis is performed.

The KMO test has a value above the threshold of 0.5 , namely 0.808 , so the components to be extracted are distinct and robust from the viewpoint of the incorporated variance, while the probability associated with the Bartlett test is 0 , therefore the correlations matrix between the considered variables is distinct from the identity matrix. A preliminary result provided by the PCA analysis comprises the complete list of principal components extracted (see Table 2).

Table 2. Total variance explained by the components extracted

\begin{tabular}{|c|c|c|c|}
\hline \multirow[b]{2}{*}{ Component } & \multicolumn{3}{|c|}{ Initial Eigenvalues } \\
\hline & Total & $\begin{array}{c}\% \text { of } \\
\text { Variance }\end{array}$ & $\begin{array}{c}\text { Cumulative } \\
\%\end{array}$ \\
\hline 1 & 4.563 & 76.053 & 76.053 \\
\hline 2 & 1.094 & 18.235 & 94.289 \\
\hline 3 & .177 & 2.955 & 97.243 \\
\hline 4 & .102 & 1.693 & 98.936 \\
\hline 5 & .062 & 1.030 & 99.966 \\
\hline 6 & .002 & .034 & 100.000 \\
\hline
\end{tabular}

Source: author, based on SPSS output

The Total column contains the eigenvalue values, meaning the variance explained by each principal component extracted successively. In the next column, these values are expressed as a percentage of the total variance. For instance, component 1 records $76.05 \%$ of total variance thus it captures a significant amount of the total variance. Component 2 explains $18.23 \%$ of indices variation from their mean, component 3 explains only $2.95 \%$ while the percentages of variance explained by the remaining components decrease progressively. The last column reflects the cumulative variance of the current and previous components. For example, the first 2 components explain $94.28 \%$ of the total variance.

By defining the main components according to the maximum variance they can explain, we have ensured that they reflect, first of all, the extreme values recorded by the variables considered, their spread or deviation from an average level. The closer to $100 \%$ is the percentage of the total variance explained, the more representative the component is for the interpretation of the considered economic phenomenon because it better captures the characteristics of the initial set of variables, their dispersion with respect to the sample average. In the subsequent analysis, only those components that prove a good ability to explain the variance of the initial set of variables will be retained.

The next stage consists in identifying the proper number of principal components that have to be extracted so that the variability remaining unincorporated is minimal.

The specialized literature proposes several selection criteria in this regard. It had been chosen the eigenvalue criterion (known also as Kaiser criterion) because it is the most commonly used and offers the best results. It imposes the condition that only the components with an eigenvalue greater than 1 should be maintained in the 
further analysis. Therefore we obtained a solution consisting of the first two components, their cumulative variance explaining $94.28 \%$ of the variability of the indices considered. In other words, the initial set of 6 indices can be reduced to two main components while the lost information is of only $5.72 \%$, corresponding to the components extracted later which did not meet the Kaiser criterion.

Alternatively, we also made a graphic representation of eigenvalue values, known as the Cattel scree plot. Those components located on the steepest slope will be selected, as the ones on the lower slope are considered to have no significant contribution.

Figure 2. Cattle selection criterion

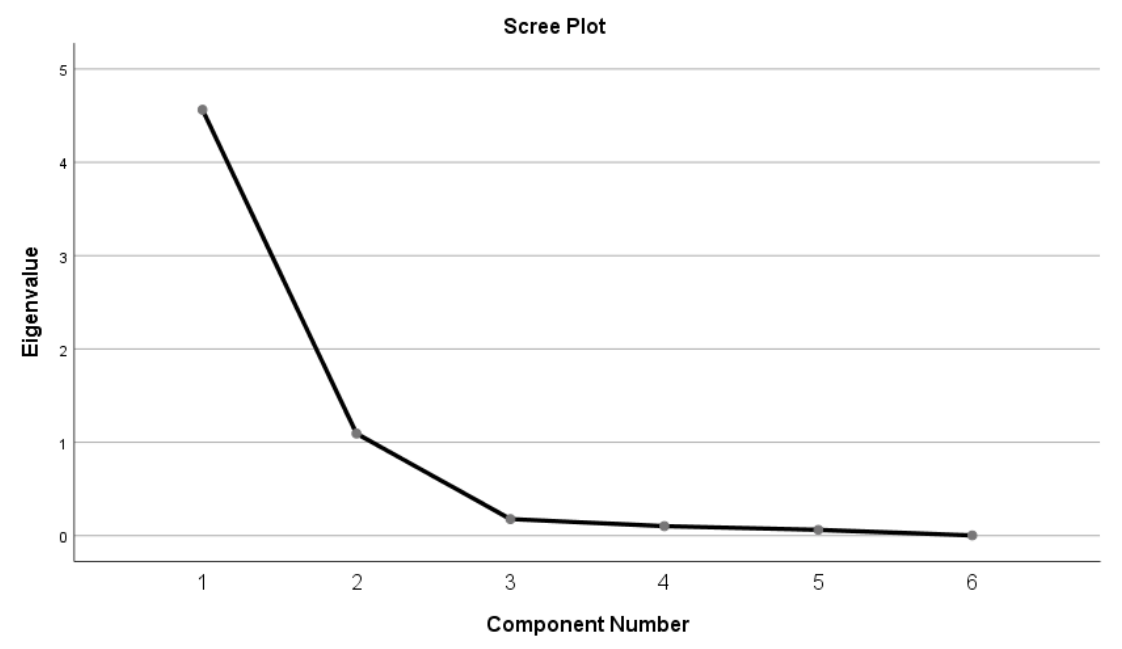

Source: author, based on SPSS output.

To facilitate the interpretation of the significance of each component, it is necessary to apply a rotation technique. We opted for an orthogonal rotation method called varimax, which ensures the uncorrelated character of the two components. In other words, a rotation of the axes takes place in a subspace, the new axes being orthogonal to each other. Once the first component has been extracted in order to explain most of the variance of the initial indices, another one will be defined that maximizes the remaining variability. Because a component is defined so as to maximize variability that was not incorporated in the previous one, consecutive components are independent of each other and uncorrelated. It is important to note that, following the rotation, the explanatory power of the components does not change. In addition, we cannot say that a certain rotation technique is superior to others, because, from a statistical point of view, all are just as good. However, in practice, the orthogonal techniques enjoy great success, especially the varimax method.

Table 3 illustrates the correlation coefficients (component loadings) computed between the indices and the principal components. It can be noticed that the $1^{\text {st }}$ component is most correlated with five DJSI indices: Europe, Japan, US, World Developed and World, while the $2^{\text {nd }}$ component is correlated only with the DJSI Emerging markets index.

Table 3. Rotated component matrix

\begin{tabular}{ccc}
\hline \multirow{2}{*}{ DJSI indices } & \multicolumn{2}{c}{ Component } \\
& 1 & 2 \\
\hline Europe & .928 & .121 \\
US & .869 & .399 \\
Japan & .978 & -.020 \\
Emerging & .062 & .983 \\
Developed & .792 & .586 \\
World & .774 & .608 \\
\hline
\end{tabular}

Note: the extraction method used is Principal Component Analysis, the rotation method employed is Varimax. Source: author, based on SPSS output.

The Component Plot in rotated space (Figure 3) provides a visual representation in a 2-dimensional space of the loadings summarized in Table 3. The purpose of the plot is to reveal how closely related the indices are to each other and to the two components. For instance, DJSI Emerging markets record a loading near zero on the first component but loads highly on the second. 
Figure 3. Visual representation of component correlations

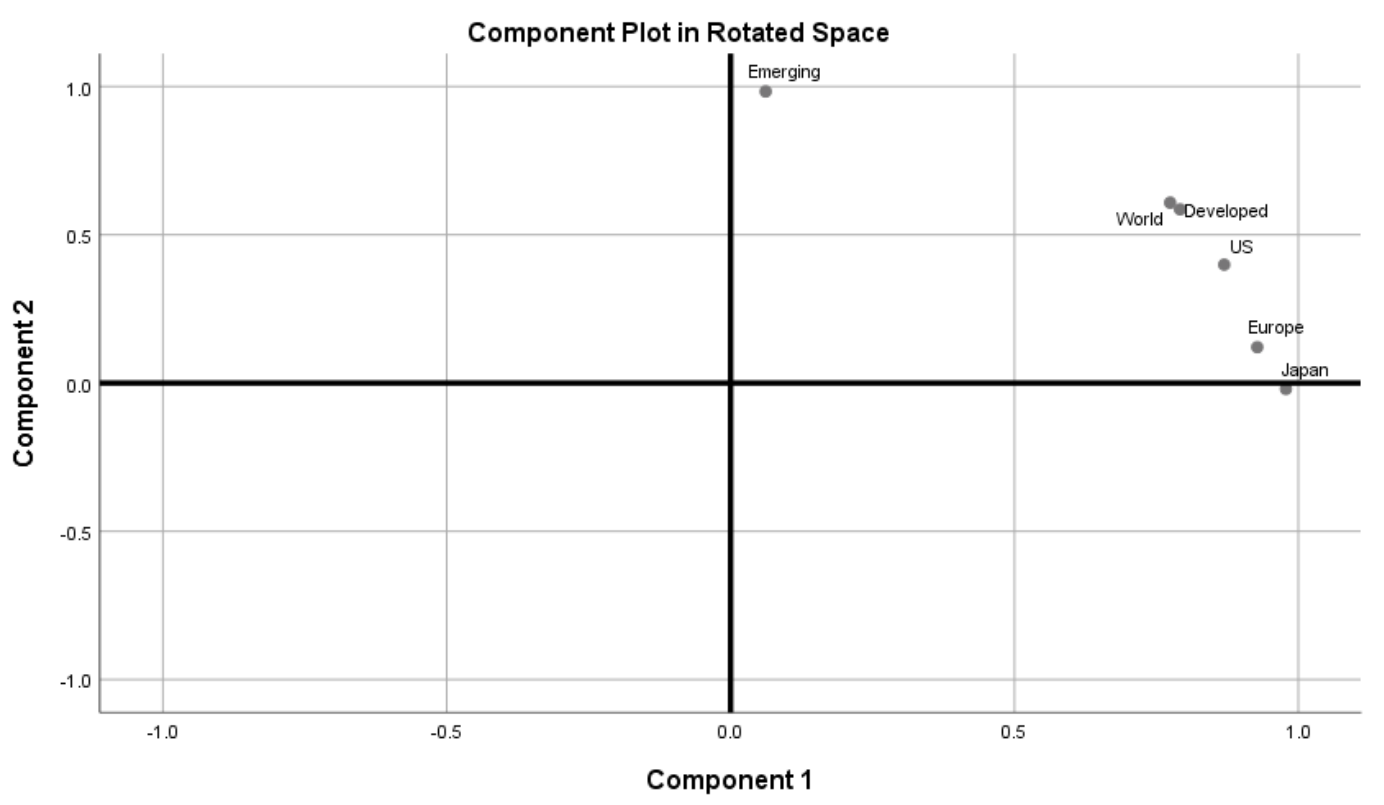

Source: author, based on SPSS output

\section{CONCLUSIONS}

Our findings are in line with those of Jain et al. (2019), although their empirical comparison was between sustainability and traditional stock market indices. More specifically, our results indicated that sustainability indices which include companies from Europe, Japan, US, World developed countries and World best-in-class exhibit correlated price returns, and hence are synchronized while DJSI for emerging countries is far apart. Therefore, the first five categories of indices may act as a substitute for each other. A second conclusion is that both the emerging market's sustainability index and any of the five indices may be included in investors' portfolios for purposes related to risk diversification and hedging.

The lack of available data for other families of sustainability indices represented a drawback invalidating our findings on other indices too or in performing the analysis so as to notice which of the different sustainability indices are correlated from the performance standpoint.

The study has practical implications, as it aims at awareness-raising of passive investors which need an ethical motivation for their investment strategy. Indirectly, their involvement will contribute to the further development of the stock markets and increased attractively of this sustainable finance product. However, the investment strategy involving sustainability indices, to be followed by each potential investor, is purely subjective, being driven by a precautionary or speculative behavior. As explained by Reynolds and Newell (2011), there is a distinction between investment and speculation. Investment is rooted in some form of market research and assessment of trends is aimed at securing a return without risking the value of the amount invested. Speculation is not usually substantiated on previous market assessments and analyses but is considered a form of gambling rather than investment.

\section{ACKNOWLEDGEMENT}

The documentation process for the elaboration of this paper was partially supported by a mobility grant of the Romanian Ministry of Research and Innovation, CNCS - UEFISCDI, project number PN-III-P1-1.1-MC-20190990, within PNCDI III.

\section{REFERENCES}

Brzeszczynski, J., \& McIntosh, G. (2014). Performance of Portfolios Composed of British SRI Stocks. Journal of Business Ethics, 120, 335-62.

Charlo, M.J., Moya, I. \& Munoz A.M. (2015). Sustainable Development and Corporate Financial Performance: A Study Based on the FTSE4Good IBEX Index. Business Strategy and the Environment, 24, 277-88.

European Sustainable Investment Forum (2011). Corporate pension funds and sustainable investment study. 
International Finance Corporation (2011). Assessing and unlocking the value of emerging markets sustainability indices, World Bank Group.

Jain M., Sharma, G.D. \& Srivastava, M. (2019). Can Sustainable Investment Yield Better Financial Returns: A Comparative Study of ESG Indices and MSCI Indices, Risks, 7, 15; DOI:10.3390/risks7010015.

Lopez, M.V., Garcia, A. \& Rodriguez, L. (2007). Sustainable development and corporate performance: A study based on the Dow Jones Sustainability Index. Journal of Business Ethics, 75, 285-300.

Reynolds, J.N. \& Newell, E. (2011). Ethics in investment banking, Palgrave Macmillan.

Santis, P., Albuquerque, A. \& Lizarelli, F. (2016). Do sustainable companies have better financial performance? A study on Brazilian public companies. Journal of Cleaner Production, 133, 735-45.

Siddy, D. (2009). Exchanges and sustainable investment, a report prepared for the World Federation of Exchanges, August 2009.

de Souza Cunha, F. A., \& Samanez, C. P. (2013). Performance Analysis of Sustainable Investments in the Brazilian Stock Market: A Study about the Corporate Sustainability Index (ISE). Journal of Business Ethics, 117, 19-36.

S\&P Dow Jones Indices (2019). Dow Jones Sustainability Indices Methodology, July 2019

Sustainable Stock Exchanges - SSE (2019). About the Sustainable Stock Exchanges Initiative, available at https://sseinitiative.org/about/about-the-sse/

Tularam, G.A., Roca, E. \& Wong, V.S.H. (2010). Investigation of Socially Responsible Investment Markets (SRI) Using Dynamic Conditional Correlation (DCC) Method: Implications for Diversification. Journal of Mathematics and Statistics, 6, 385-94.

Vives A. \& Wadhwa, B. (2012). Sustainability indices in emerging markets: impact on responsible practices and financial market development, Journal of Sustainable Finance \& Investment, vol. 2(3-4), pages 318-337, October.

World Federation of Exchanges, (2018). WFE Sustainability Principles, available at https://www.worldexchanges.org/storage/app/media/research/Studies_Reports/2018/WFE\%20Sustainability\%20Principles\%20October $\% 202018$.pdf 